\title{
The inferior oblique as muscle of choice for biopsies of extraocular muscles
}

\author{
T. U. HOOGENRAAD, ${ }^{1}$ K. E. W. P. TAN, ${ }^{2}$ H. J. W. EELDERINK, ${ }^{1}$ \\ H. VELDMAN, ${ }^{1}$ AND F. G. I. JENNEKENS ${ }^{1}$
}

From the ${ }^{1}$ Laboratory for Neuromuscular Diseases, Department of Neurology, State University Hospital, Utrecht, and ${ }^{2}$ Department of Ophthalmology, State University Hospital, Utrecht, The Netherlands

SUMMARY Suitable biopsies can easily be taken from the inferior oblique muscle without unwanted side effects from the belly of this muscle, allowing complete examination by light and electron microscopy. The inferior oblique is the muscle of choice for biopsy studies of extraocular muscle.

Investigations performed on biopsy material from limb muscles have contributed greatly to knowledge of neuromuscular diseases. Extraocular muscles (EOM) are distinct from other skeletal muscles in physiological, morphological, and histochemical respects (Hess and Pilar, 1960; Harker, 1972; Peachy et al., 1974; Durston, 1974; Ringel et al., 1978). Biopsies from EOM in ophthalmoplegia have been investigated only occasionally, however.

There are at least three reasons for this reserved attitude. Firstly, it is imperative to exercise caution in performing eye muscle biopsy so that ocular motility is not impaired (Ringel et al., 1978). The physician in charge is often not familiar with eye muscle surgery and may be anxious about ocular motility. Secondly, whereas the muscle belly is the most suitable part in the muscle for biopsy purposes (Dubowitz and Brooke, 1973), most EOM bellies lie deep in the orbit and are not easily accessible. Thirdly, pathological changes in EOM differ in many respects from those in limb muscles, and their evaluation is difficult because many criteria applicable to limb muscles cannot be used (Drachman et al., 1969; Goebel et al., 1974; Harriman, 1975).

The aim of the present paper is to demonstrate that the inferior oblique is the muscle of choice for EOM biopsies. Sufficient material for adequate morphological and histochemical investigations can be taken from this muscle without unwanted side effects.

\section{Material and methods}

Biopsies from inferior oblique muscle were taken in 16 patients. All these patients had complaints of

Address for reprints: Dr T. U. Hoogenraad
Table 1 Clinical details of patients

\begin{tabular}{lllllll}
\hline Patient & Sex & Side & $\begin{array}{l}\text { Age } \\
\text { (yr) }\end{array}$ & $\begin{array}{l}\text { Light } \\
\text { micro- } \\
\text { scopy }\end{array}$ & $\begin{array}{l}\text { Electron } \\
\text { micro- } \\
\text { scopy }\end{array}$ & Clinical diagnosis \\
\hline 1 & M & R & 6 & + & & $\begin{array}{l}\text { Congenital oculomotor } \\
\text { weakness }\end{array}$ \\
2 & M & L & 21 & + & + & $\begin{array}{l}\text { Mitochondrial } \\
\text { myopathy }\end{array}$ \\
3 & M & L & 25 & + & + & Exophthalmus \\
4 & M & L & 30 & + & & Dystrophia myotonica \\
5 & M & R & 48 & + & & Hereditary ataxia \\
6 & M & R & 48 & + & + & Ocular myasthenia \\
7 & M & R & 51 & + & & Ocular myopathy \\
8 & M & L & 52 & + & + & Ocular myasthenia \\
9 & M & L & 61 & + & + & Ocular myasthenia \\
10 & M & L & 72 & + & & Ocular myasthenia \\
11 & F & R & 54 & + & + & Atrophia faciei \\
12 & M & R & 31 & + & + & Ocular myopathy \\
13 & M & L & 55 & + & + & Ocular myasthenia \\
14 & M & R & 47 & + & + & Ocular myasthenia \\
15 & M & R & 50 & + & + & Oculomotor paralysis \\
16 & M & R & 35 & + & + & Ophthalmoplegia plus \\
\hline & & & & & & \\
\hline
\end{tabular}

ptosis or diplopia (Table 1), and all had been examined ophthalmologically and neurologically. Biopsy was recommended when it was considered likely that the examination might yield information to aid diagnosis and treatment. Every patient was given an outline of the procedure in advance. The biopsy was preferably taken under local anaesthesia, but in 5 cases it was performed during a surgical 
operation for ptosis or strabismus done under general anaesthesia.

\section{SURGICAL TECHNIQUE}

Good accessibility of the distal half of the inferior oblique muscle is obtained by rotating the eyeball inwards and upwards. The muscle is approached by a horizontal incision in the inferior temporal quadrant of the conjunctiva and Tenon's capsule, just above the upper margin of the muscle. The muscle fascia is dissected bluntly. The muscle is engaged under direct vision with the help of 2 muscle hooks, and 10 to $15 \mathrm{~mm}$ of the inferior oblique is exposed in this way. A double-ended clamp is placed on the upper part of the muscle. The distance between the 2 ends of the clamp is $4 \mathrm{~mm}$. A second and smaller clamp (distance between the clamp ends $2 \mathrm{~mm}$ ) is placed next to the first one. The muscle is cut on both outer sides of the clamps, and the segments, still held in the clamps, are excised. The muscle is now allowed to retract and the conjunctival incision is closed by suture.

\section{LABORATORY TECHNIQUE}

The specimen held in the larger clamp is frozen in isopentane, cooled in liquid nitrogen and is transferred to a cryostat. The frozen specimen is freed from the clamp with a goldsmith's fretsaw (Miller, 1967). The specimen is mounted on a small piece of cork and orientated as an upright cylinder. Transverse sections may now be cut and stained by routine histological and histochemical methods. The specimen held in the small clamp is placed immediately in an ice-cold cacodylate-buffered $2 \%$ glutaraldehyde solution.

After 10 minutes the clamp is opened and the specimen is divided into smaller pieces. It is prepared for electron microscopy according to standard methods.

\section{Results}

After biopsy all patients were examined regularly for 14 days. No unwanted side effects were observed. Patients operated on only for biopsy found the procedure to be not very painful. Minor discomfort was reported during the first days after operation. None complained of increase of diplopia. Examination showed no increase of weakness of the inferior oblique muscle.

The cryostat sections were approximately $2 \times 2$ $\mathrm{mm}$. They confirmed that the biopsy had been taken from the fleshy part of the muscle. The sections contained tissue from both peripheral and central parts of the muscle (Figs. 1 and 2). Sufficient material for 2 histological stainings and 5 to 10

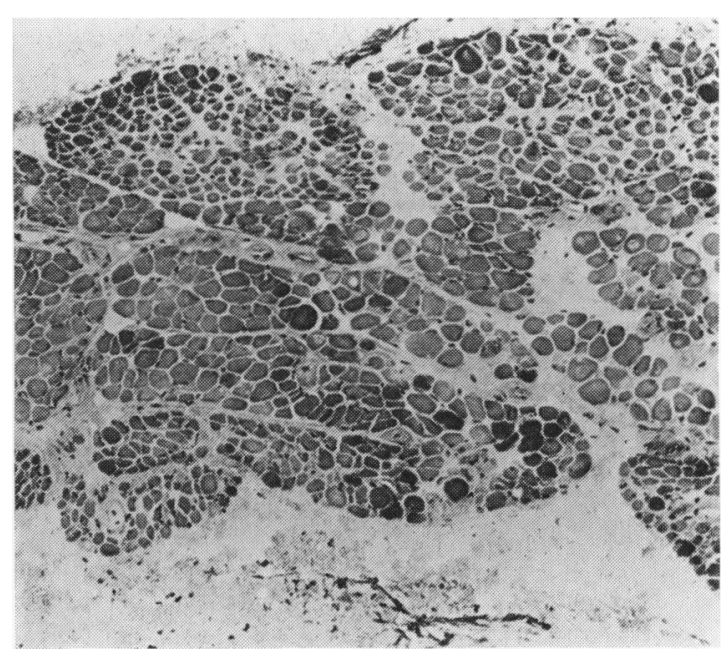

Fig. 1 Case 15. Clinical diagnosis: oculomotor paralysis. Inferior oblique muscle. Peripheral and central areas in cross-section. Frozen section. Haematoxylin and eosin $(\times 80)$

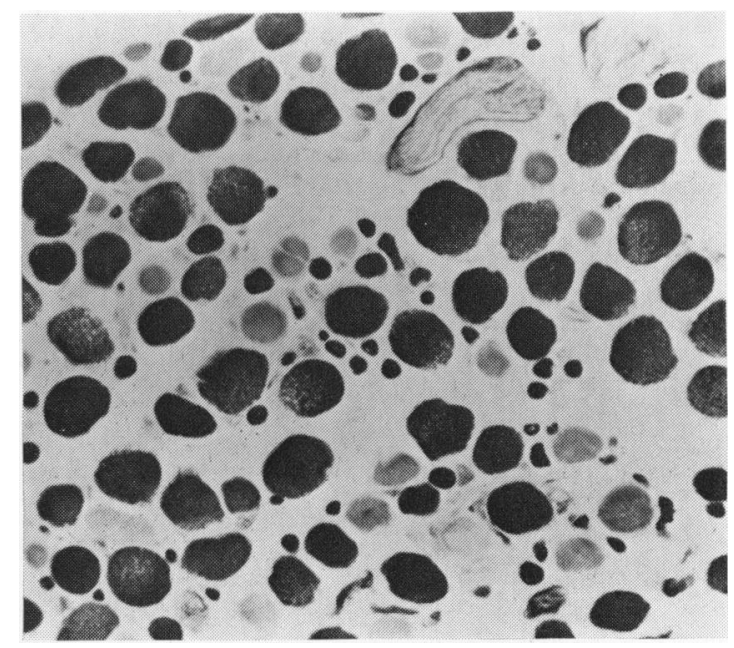

Fig. 2 Case 1. Clinical diagnosis: congenital oculomotor weakness. Inferior oblique muscle. Central area. Frozen section. Myosin-ATPase, pH 9.4 ( $\times 240)$

histochemical techniques was available, and in all cases the stainings could be repeated once or several times in fresh sections when this was needed.

The size of the cryostat sections from Case 2 was insufficient for adequate histological and histochemical investigations. Sections from this material contained approximately 100 fibres. Tissue from 11 patients were fixed and embedded for electron microscopy. Some artefactual damage of the specimen was present, but adequate examination was possible in all cases (Figs. 3 and 4). 


\section{Discussion}

An account of the first biopsy study of extraocular muscles was published more than three decades ago by Sandifer (1946). He used material from the external rectus muscle, and his example was followed

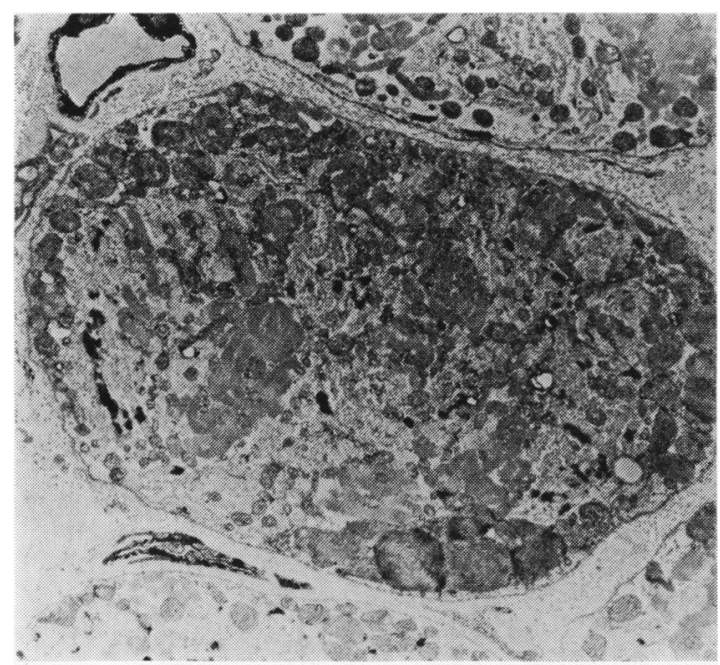

Fig. 3 Case 2. Clinical diagnosis: mitochondrial myopathy. Inferior oblique muscle. Electron microscopy $(\times 3200)$ by most other authors. Only a few studies on the inferior oblique muscle have been reported (Schlote and Körner, 1975; Mukuno et al., 1976; Hoogenraad et al., 1977). Initially we also used the external rectus for biopsy.

The results were usually disappointing, as the biopsies often contained predominantly fibrous and tendinous tissue and relatively few muscle fibres. We suggest that for at least three reasons the inferior oblique muscle is to be preferred for biopsy studies of EOM. Firstly, it has been shown that the inferior oblique is highly resistant to weakening by myectomy. Helveston (1973) reports that in stabismus surgery large muscle resections may be done and even subtotal myectomies without crippling the muscle. Secondly, the tendinous part of a muscle is not suitable for biopsy examination. The inferior oblique is unique in having an extremely short tendinous ending, so being fleshy throughout nearly all its length. According to Crone (1973) the length of the tendon is less than $1 \mathrm{~mm}$ in the inferior oblique but varies between 3.7 and $30 \mathrm{~mm}$ in other EOM. Thirdly, the belly of the inferior oblique, in contrast to that of other EOM, is easily accessible, as it lies in the anterior part of the orbit.

The results presented in this paper and case studies reported elsewhere (Hoogenraad et al., 1977; Hoogenraad et al., 1978) show that investigations of large numbers of fibres are readily undertaken

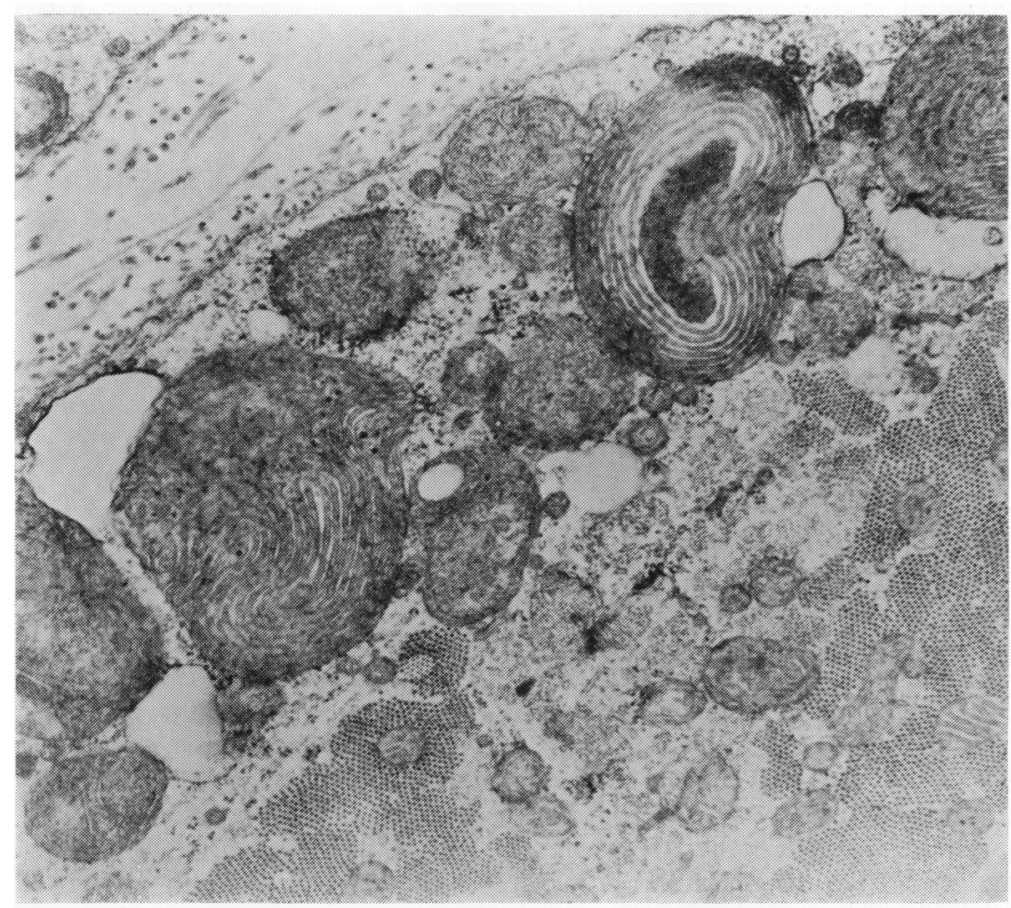

Fig. 4 Case 2. Clinical diagnosis: mitochondrial myopathy. Inferior oblique muscle. Electron microscopy $(\times 8500)$ 
with all currently used morphological and histochemical techniques in the peripheral and central zones of inferior oblique biopsies. Data on the histology and the histochemical fibre types in this muscle are available (Hoogenraad et al., 1979).

We are grateful to Dr A. G. M. van Vliet, Academic Hospital, Dijkzicht, Rotterdam, Dr J. van Manen, Academic Hospital, Wilhelmina Gasthuis, Amsterdam, and Dr A. R. Wintzen, Academic Hospital, Leiden, for referring patients for biopsy investigations.

We thank Mrs Els Hoogenraad-Breijer, Mrs Joke van Essen, Mr A. P. Piso, and Mr T. Wollenberg for their assistance in the preparation of this manuscript.

\section{References}

Crone, R. A. (1973). Diplopia, pp. 37-38. Excerpta Medica: Amsterdam.

Drachman, D. A., Wetzel, N., Wasserman, M., and Naito, H. (1969). Experimental denervation of ocular muscles: a critique of the concept of 'ocular myopathy'. Archives of Neurology, 21, 170-183.

Dubowitz, V., and Brooke, M. H. (1973). Muscle Biopsy: A Modern Approach, p. 6. Saunders: London, Philadelphia, Toronto.

Durston, J. H. J. (1974). Histochemistry of primate extraocular muscles and changes of denervation. British Journal of Ophthalmology, 58, 193-216.

Goebel, H. H., Helveston, E., and Eichholtz, W. (1974). Histochemistry of extraocular muscles. IIIrd international congress on muscle diseases. Abstract 41. 17-18, International congress series no. 334.

Harker, D. W. (1972). The structure and innervation of sheep superior rectus and levator palpebrae extraocular muscles. Investigative Ophthalmology, 11, 956-969.

Harriman, D. G. F. (1975). Histochemical fibre types in human extraocular muscle. Bristol Medico-Chirurgical Journal, 90, 27-29.

Helveston, E. M. (1973). Atlas of Strabismus Surgery, pp. 18-100. Mosby: St. Louis.
Hess, A., and Pilar, G. (1960). Slow fibres in the extraocular muscle. Journal of Physiology, 153, 522-526.

Hoogenraad, T. U., Jennekens, F. G. I., and Tan, K. E. W. P. (1977). Histochemistry of inferior oblique muscle in a case of congenital third nerve palsy. Documenta Ophthalmologica, 44, 187-192.

Hoogenraad, T. U., Jennekens, F. G. I., and Tan, K. E. W. P. (1978). Ophthalmoplegia due to myasthenia gravis. Histological and histochemical observations in the inferior oblique muscle. In Proceedings of the 5th international congress of neurogenetics and neuro-ophthalmology, Nijmegen, The Netherlands, 1977. Documenta Ophthalmologica Proceeding Series, vol. 17, p. 27. Edited by A. F. Deutman and J. R. M. Cruysberg. Junk: The Hague, Boston, London.

Hoogenraad, T. U., Jennekens, F. G. I., and Tan, K. E. W. P. (1979). Histochemical fibre types in human extraocular muscles, an investigation of inferior oblique muscle. Acta Neuropathologica, 45, 73-78.

Miller, J. E. (1967). Cellular organization of rhesus extraocular muscle. Investigative Ophthalmology, 6, 18-39.

Mukuno, K., Ishikawa, S., Togo, T., and Minei, Y. (1976). Histopathological study on the overacted inferior oblique muscles with special reference to 'central core' within the muscle fibres. Japanese Journal of Ophthalmology, 20, 166-176.

Peachy, L. D., Takeichi, M., and Nag, A. C. (1974). Muscle fibre types and innervation in adult cat extraocular muscles. In Exploratory Concepts of Muscular Dystrophy, II. Edited by A. T. Milhorat. International congress series, no. 333, pp. 246-254. Excerpta Medica: Amsterdam.

Ringel, S. P., Wilson, B., Barden, M. T., and Kaiser, K. K. (1978). Histochemistry of human extraocular muscle. Archives of Ophthalmology, 96, 1067-1072.

Sandifer, P. H. (1946). Chronic progressive ophthalmoplegia of myopathic origin. Journal of Neurology, Neurosurgery, and Psychiatry, 9, 81-83.

Schlote, W., and Körner, F. (1975). Chronic progressive external ophthalmoplegia - a neuro-muscular disorder. In Basic Mechanisms of Ocular Motility and their Clinical Implications. Proceedings of the International Symposium held in Wenner-Gren Centre, Stockholm, 1974, pp. 549553. Edited by G. Lennerstrand and P. Bach-y-Rita. Pergamon Press: Oxford. 